DOI: 10.12731/2658-6649-2020-12-1-23-33

УДК 582.572.8 (470.47)

\title{
ПЛОТНОСТЬ И ВИТАЛИТЕТНАЯ СТРУКТУРА ЦЕНОПОПУЛЯЦИЙ TULIPA BIFLORA PALL. (LILIACEAE) В ПРИКАСПИЙСКОЙ НИЗМЕННОСТИ
}

\author{
Очирова А.C.
}

Цель. Характеристика плотности и виталитетной структуры ценопопуляций Tulipa biflora Pall. (Liliaceae) в Прикаспийской низменности (в пределах Республики Калмыкия).

Материаль и методы. Материалом для исследований послужили две видовые популяции тюльпана двуцветкового, произрастающие в естественных растительных сообществах в Прикаспийской низменности. Выделение онтогенетических состояний отдельных растений тюльпана двуцветкового и учет плотности производили в соответствии с классическими методиками, модифицированными к луковичным эфемероидам.

Оиенку жизненности иенопопуляций тюльпана двуцветкового в трехлетний период исследования производили с помощью определения критерия $Q$ по Ю.А. Злобину и индекса жизненности IVC.

Результаты. Плотность растений тюльпана двуияеткового в популячии № 1 составила в среднем на 0,25 кв.м в 2013 году 26,3, в 2014 году - 15,2, в 2015 году-10,9 растения. В период исследования плотность растений тюльпана двуиветкового в популяичии № 2 была значительно больше, чем в иенопопулящии № 1 .

В популяциях тюльпана двуцветкового плотность была наибольшей в первый год исследования и составила в среднем 26,3-29,9 растения на 0,25 кв.м., в два последующих года была она существенно ниже.

Анализ температурных данных и объема осадков в течение марта месяиа, предшествующего вегетации растений тюльпана двуцветкового, выявил, что частота растений вида в обеих популяциях была скоррелирована с объемом выпавших осадков.

В двух исследованных иченопопулящиях тюльпана двуцветкового в период исследования частость разных классов виталитета была характерной для депрессивных иеенопопуляиий. Принадлежность их к данному вита- 
литетному типу подтвердили также вычисленные значения индексов жизненности $Q$ и IVC.

Заключение. В Прикаспийской низменности в условиях природных фитоценозов плотность растений в цүенопопуляциях тюльпана двуцветкового составляла 14,2-29,9 особей на 0,25 кв.м. Популяции тюльпана двуцвветкового в Прикаспийской низменности в трехлетний период исследования относились к депрессивному виталитетному типу.

Ключевые слова: цуенопопуляцчия; тюльпан двуцзветковый; плотность; виталитетная структура популячии .

\section{DENSITY AND VITALITY STRUCTURE OF POPULATIONS OF TULIPA BIFLORA PALL. (LILIACEAE) IN THE CASPIAN LOWLAND}

\section{Ochirova A.S.}

Background. The characterization of the density and vitality structure of populations of Tulipa biflora Pall. (Liliaceae) in the Caspian lowland (within the Republic of Kalmykia).

Materials and methods. Two species populations of the two-flowered Tulip growing in natural plant communities in the Caspian lowland served as the material for the research. Isolation of ontogenetic States of individual Tulip plants and density accounting was performed in accordance with classical methods modified to bulbous ephemeroids.

Assessment of the vitality of the two-flowered Tulip cenopopulations in the three-year period of the study was performed by determining the criterion $Q$ by Yu. A. Zlobin and the vitality index IVC.

Results: The density of Tulip plants in population № 1 was an average of 0,25 sq. m. in 2013 26,3, in 2014-15,2, in 2015-10,9 plants. During the study period, the density of Tulip plants in population № 2 was significantly higher than in coenopopulation № 1 .

In the populations of the two-flowered Tulip, the density was highest in the first year of the study and averaged 26,3-29,9 plants per 0,25 sq. m., in the next two years it was significantly lower.

The analysis of temperature data and precipitation during March the month preceding the vegetation of Tulip plants revealed that the frequency of plants of the species in both populations was correlated with the amount of precipitation. 
In the two studied coenopopulations of the two-flowered Tulip during the study period, the frequency of different classes of vitality was characteristic of depressive coenopopulations. Their belonging to this vital type was also confirmed by the calculated values of the vitality indices $Q$ and IVC.

Conclusion. In the Caspian lowland under the conditions of natural phytocenoses, the density of plants in the coenopopulations of the two-flowered Tulip was 14,2-29,9 individuals per 0,25 sq. m. the Populations of the two-flowered Tulip in the Caspian lowland in the three-year period of the study belonged to the depressive vital type.

Keywords: coenopopulation; two-flowered Tulip; density; vital structure of the population.

Во флоре Республики Калмыкия особенно подвержены угрозе сокращения численности виды из семейства Лилейные в связи с возрастающим антропогенным воздействием. В числе работ, в которых исследовали биоморфологию, цитологию и популяционную экологию представителей Лилейных [1-9 и др.], мало проведенных в аридных условиях [10].

Объект проведенного исследования - тюльпан двуцветковый (Tulipa biflora Pall.), являющийся представителем семейства Liliaceae, подлежит к охране в ряде регионов России [11-13]. В региональной Красной книге [14] тюльпан двуцветковый имеет категорию редкости «редкий вид».

В связи с вышеизложенным, целью исследования явилась характеристика плотности и виталитетной структуры ценопопуляций Tulipa biflora Pall. (Liliaceae) в Прикаспийской низменности.

В нашей работе в течение трех лет исследованы две видовые популяции тюльпана двуцветкового, одна из которых, ценопопуляция № 1 , входила в состав эфемерово-луковичномятликово - полынного (Artemisia Poabulbosa - Ephemerosa) фитоценоза, другая, ценопопуляция № 2, - в состав луковичномятликово-лерхополынного (Artemisia lerchiana - Poa bulbosa) фитоценоза. Оба сообщества приурочены к бурым пустынно-степным солонцеватым почвам. Поскольку тюльпан двуцветковый является моцентрической биоморфой, счетной единицей в популяции вида считали самостоятельный растительный организм, представляющий собой особь семенной репродукции [15-17].

В пределах фитоценозов, к которым приурочены исследуемые популяции тюльпана двуцветкового, были заложены транссекты из десяти площадок таким образом, чтобы вошли типичные места обитания вида в сообществе $[15,16]$. На всех площадках проводили подсчет особей раз- 
ных онтогенетических состояний. Плотность рассматривали как среднее для данной популяции число особей на учетной площадке размером 0,5х0,5 кв.м.

Выделение онтогенетических состояний отдельных растений проводили в соответствии с классическими методиками, модифицированными к луковичным эфемероидам $[18,19]$.

Оценку виталитетной структуры популяций проводили, используя морфологические признаки растений по методу Ю.А. Злобина [17] с определением критерия Q и через определение индекса жизненности IVC [20], которые позволили затем произвести ранжирование популяций по уровню их жизненности. При вычислении обоих показателей жизненности использовали высоту растений, поскольку данный признак, из всех возможных изучить на живых растениях в естественных условиях произрастания, является одним из наиболее показательных в отношении характеристики виталитета.

Одной из характеристик популяций растений, позволяющих оценить их состояние является плотность. Плотность растений тюльпана двуцветкового в популяции № 1 в трехлетний период исследования варьировала от 5 до 44 особей, составив в среднем на 0,25 кв.м в 2013 году 26,3, в 2014 году - 15,2, в 2015 году - 10,9 растения. Предельные частоты растений тюльпана двуцветкового на учетных площадках в период исследования в популяции № 2 составили 6-38 особей, обнаружив в среднем на 0,25 кв.м в 2013 году 29,9, в 2014 году - 18,2, в 2015 году - 14,2 растения. В период исследования плотность растений тюльпана двуцветкового в популяции № 2 больше, чем в ценопопуляции № 1.

В популяциях тюльпана двуцветкового плотность была наибольшей в первый год исследования (2013 г.) и составило в среднем 26,3-29,9 растения на 0,25 кв.м. В популяции № 1 на следующий год среднее число растений на учетной площадке уменьшилось на 15,2 (tdiff $=3,32$, при $\mathrm{P}<0,05)$, в последний год исследования - на 10,9 (tdiff=4,57, при $\mathrm{P}<0,05$ ) растений на 0,25 кв.м. В популяции № 2 в сравнении с первым годом исследования это различие было особенно сильно в 2015 г. - 14,2 (tdiff=5,20, при $\mathrm{P}<0,05)$ растений (рис. 1).

Поскольку в рассматриваемый трехлетний период исследования основными изменяющимися показателями в окружающей обе популяции среде были погодные условия, то полученные данные по плотности растений были сопоставлены с основными климатическими факторами. Анализ температурных данных и объема осадков в течение марта (месяца предшествующего вегетации растений тюльпана двуцветковоговыявил, что частота растений вида в обеих популяциях коррелирует с объемом выпавших осадков (рис. 2). 


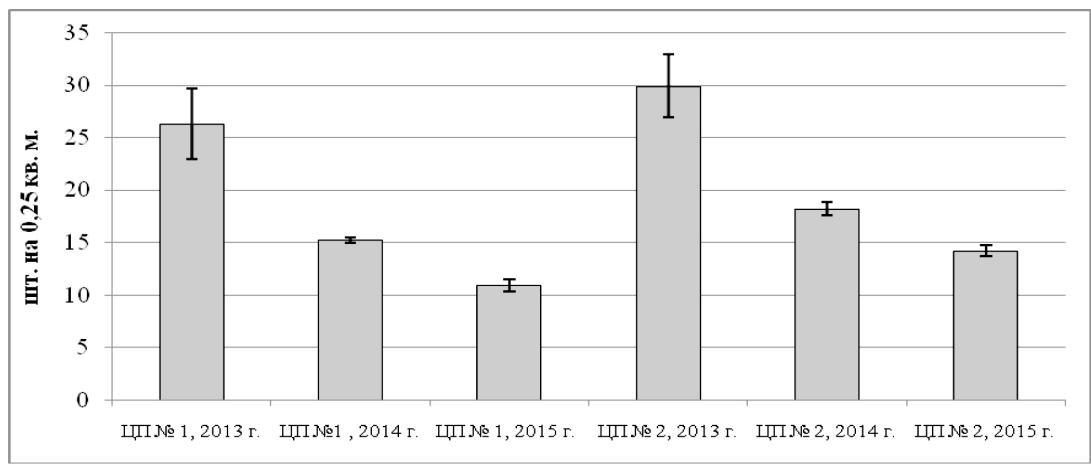

Рис. 1. Плотность растений (шт./на $0,25 \mathrm{~m}^{2}$ ) в популяциях тюльпана двуцветкового: ЦП - ценопопуляция
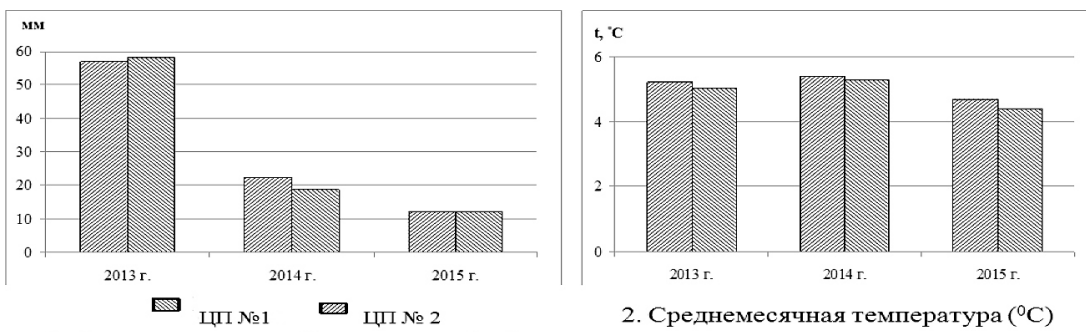

1. Среднемесячный объем осадков (мм)

Рис. 2. Среднемесячные объем осадков (мм) и температура $\left({ }^{\circ} \mathrm{C}\right)$ марта в годы исследования в местах произрастания тюльпана двуцветкового по данным метеостанций: ЦП - ценопопуляция

Определению индекса жизненности Q по Ю.А. Злобину [10] предшествовало распределение особей по классам виталитета. В ценопопуляции № 1 тюльпана двуцветковогов первый год исследования данное распределение выглядело таким образом: частость класса «а» (высокие растения) достигала 0,43 ; класса «b» (растения с промежуточным ростом) - 0,15; класса «с» (низкие растения) - 0,41. Индекс жизненности Q в данной ценопопуляции имел в этот год значение 0,29 и он значительно меньше частости особей в классе «с», что позволило определить виталитетный тип ценопопуляции № 1 как «депрессивный».

В 2014 году в данной ценопопуляции уменьшилась доля растений класса «а» на 10,6\%, в то время как доля особей классов «b» и «с» возросла на 3,9 и $6,6 \%$ соответственно, что привело к снижению индекса Q до 0,25 , что свидетельствует об еще большем уровне депрессивности популяции. 
В последний год исследования по трем классам виталитета отмечалась обратная тенденция в сравнении с 2014 годом: возрастание доли класса «а» на 14,5\% и снижение доли растений двух других классов. Это обусловило увеличение индекса жизненности до 0,28 , однако популяция сохранила свой депрессивный статус (рис. 3,4 ).

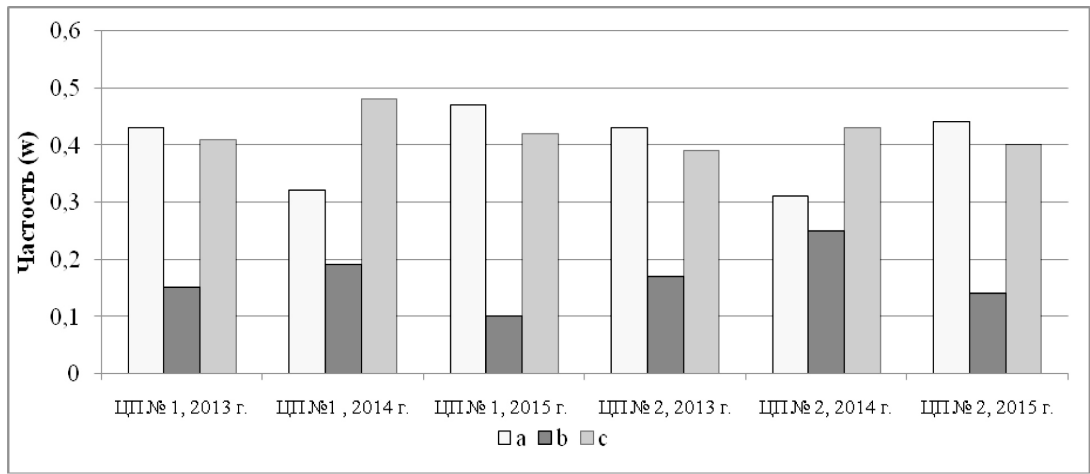

Pис. 3. Типы виталитетных спектров ценопопуляций тюльпана двуцветкового в годы исследования: ЦП - ценопопуляция

В ценопопуляции № 2 тюльпана двуцветкового в в три года исследования частость разных классов виталитета была также характерной для депрессивных ценопопуляций: для класса «а» от 0,31 в 2014 году до 0,44 в 2015 году, для класса «b» - от 0,14 в 2015 году до 0,25 в 2014 году, класса «с»- от 0,39 в 2013 году до 0,43 в 2015 году. Значение индекса Q в период исследования в 2015 году возросло в сравнении с двумя предыдущими годами исследования.

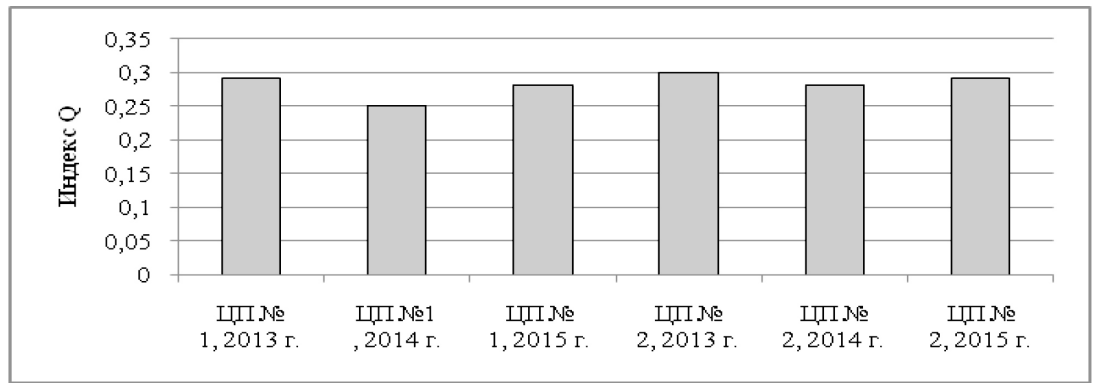

Рис. 4. Оценка жизненности ценопопуляций тюльпана двуцветкового по размерному спектру Q: ЦП - ценопопуляция 
Другой индекс жизненности - IVC, при его использовании для характеристики виталитетной структуры обеих популяций тюльпана двуцветкового, произрастающих в Прикаспийской низменности, варьировал в период исследования в ценопопуляции № 1 на уровне $0,88-0,91$; в ценопопуляции № 2 - 1,09-1,12. При этом в ценопопуляции № 2 во все три года исследований значения индекса IVC большие в сравнении с ценопопуляцией № 2, что свидетельствует, на наш взгляд, о более предпочтительных для вида экотопических условий для произрастания растений (рис. 5).

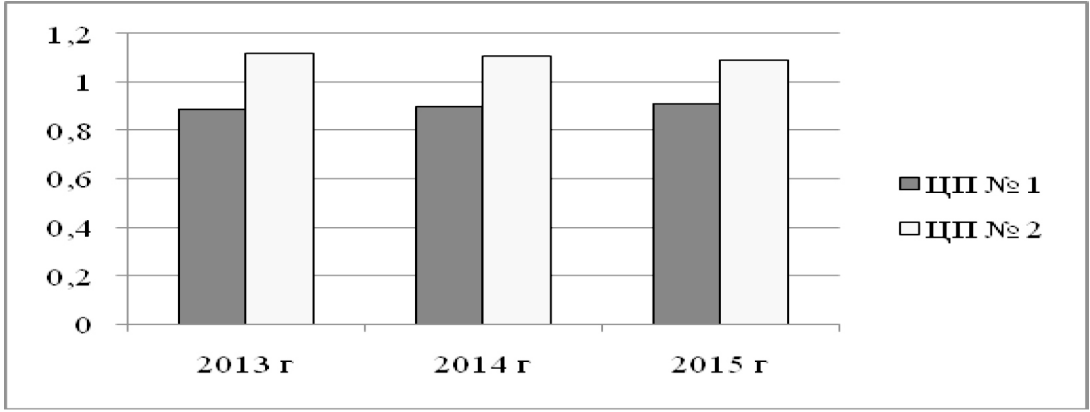

Рис. 5. Оценка жизненности ценопопуляций тюльпана двуцветкового по индексу виталитета IVC: ЦП - ценопопуляция

\section{Заключение}

В Прикаспийской низменности в условиях природных фитоценозов плотность растений тюльпана двуцветкового ценопопуляциях варьировала от 14,2 до 29,9 особей на 0,25 кв.м. На динамику плотности растений в ценопопуляциях по годам существенное влияние оказывали климатические условия года, особенно объем осадков.

Популяции тюльпана двуцветкового в Прикаспийской низменности в трехлетний период исследования, несмотря на их разную эколого-фитоценотическую принадлежность, относились к депрессивному виталитетному типу.

Полученные данные пополнят базу данных по биологии и экологии тюльпана двуцветкового в аридных условиях, могут стать основой мониторинга состояния данных ценопопуляций.

\section{Список литературы}

1. Мухаметшина Л.В., Муллабаева Э.З., Ишмуратова М.М. Изменчивость морфологических признаков некоторых видов рода Tulipa L. на Южном 
Урале // Известия Самарского научного центра Российской академии наук. 2014. T. 16. №. 5-5. С. 1650-1653.

2. Мухаметшина Л.В., Муллабаева Э.З., Ишмуратова М.М. Особенности биологии и ценопопуляционные характеристики видов рода Tulipa L. на Южном Урале // Вестник Удмуртского университета. Серия «Биология. Науки о Земле». 2015. №. 2. С. 101-108.

3. Рябинина 3.Н., Диденко Е.Н. Популяционные исследования некоторых видов семейства Liliaceae // Известия Оренбургского государственного аграрного университета. 2007. Т. 3. №. 15-1. С. 19-23.

4. Структура ценопопуляций Tulipa gesneriana L.(Liliaceae) в Саратовской области / Кашин А.С., Петрова Н.А., Шилова И.В., Корнеев М.Г., Ермолаева Н.Н. // Биоразнообразие аридных экосистем. 2014. С. 86-105.

5. Kutlunina N.A., Polezhaeva M.A., Permyakova M.V. Morphologic and AFLP analysis of relationships between tulip species Tulipa biebersteiniana (Liliaceae) // Russian journal of genetics, 2013, vol. 49, no 4, pp. 401-410.

6. Shorina N.I., Smirnova O.V. The Population Biology of Ephemeroids // The Population Structure of Vegetation. Springer, Dordrecht, 1985, pp. 225-240.

7. Zonneveld J.M. The systematic value of nuclear genome size for «all» species of Tulipa L. (Liliaceae) // Plant Systematics and Evolution, 2009, vol. 281, pp. 217-245.

8. Chernysheva O., Bukin Y., Krivenko D. The morphometric characters variability analysis of Tulipa uniflora (Liliaceae) in the Angara Region (Irkutsk Oblast, Russia) // BIO Web of Conferences. EDP Sciences, 2018, 21 August 2018, vol. 11. P. 00009.

9. Van Raamsdonk L.W.D., De Vries T. Species relationships and taxonomy in Tulipa subg. Tulipa (Liliaceae) // Plant Systematics and Evolution, 1995, vol. 195, no. 1-2, pp. 13-44.

10. Нгок Л.Т., Очирова А.С., Лиджиева Н.Ц. Изменчивость морфологических признаков растений и виталитетная структура ценопопуляций видов рода Tulipa (Liliaceae) в заповеднике «Черные земли» // Известия Самарского научного центра Российской академии наук. 2016. Т. 18. №. 5-2. С. 314-319.

11. Красная книга Российской Федерации (растения и грибы) / сост. Р. В. Камелин и др. М.: Товарищество научных изданий КМК, 2008. 885 с.

12. Красная книга Краснодарского края. (Растения и грибы) / Отв. ред. С.А. Литвинская. 2-е изд. Краснодар: ООО «Дизайн Бюро № 1», 2007. 640 с.

13. Красная книга Ростовской области: в 2 т. Растения и грибы / Науч. ред. В.В. Федяева. Ростов-на-Дону: Минприроды Ростовской области, 2014. T. $2.344 \mathrm{c}$. 
14. Красная книга Республики Калмыкия: в 2 т. Редкие и находящиеся под угрозой исчезновения растения и грибы / отв. ред. Н.М. Бакташева. Элиста: ЗАОр «НПП «Джангар», 2014. Т.2. 199 с.

15. Ценопопуляции растений (основные понятия и структура) / Отв. ред. А.А. Уранов, Т.И. Серебрякова. М.: Наука, 1976. 217 с.

16. Ценопопуляций растений / Отв. ред. Т.И. Серебрякова. М.: Наука, 1977. $173 \mathrm{c}$.

17. Злобин Ю.А. Принципы и методы изучения ценотических популяций растений. 1989. 146 с.

18. Уранов А.А. Жизненное состояние вида в растительном сообществе // Бюл. МОИП. Отделение биол. 1960. Т. 65. Вып. 3. С. 77-92.

19. Уранов А.А. Онтогенез и возрастной состав популяций // Онтогенез и возрастной состав популяций цветковых растений. М.: Наука, 1967. С. 3-8.

20. Ишбирдин А.Р., Ишмуратова М.М. К оценке виталитета ценопопуляций Rhodiola iremelica Boriss. по размерному спектру // Фундаментальные и прикладные проблемы популяционной биологии. 2004. С. 80-85.

\section{References}

1. Mukhametshina L.V., Mullabaeva E.Z., Ishmuratova M.M. Izmenchivost' morfologicheskikh priznakov nekotorykh vidov roda Tulipa L. na Yuzhnom Urale [Variability of morphological features of some species of the genus Tulipa L. in the southern Urals]. Izvestiya Samarskogo nauchnogo tsentra Rossiyskoy akademii nauk [Izvestiya Samara scientific center of the Russian Academy of Sciences], 2014, V. 16, no. 5-5, pp. 1650-1653.

2. Mukhametshina L.V., Mullabaeva E.Z., Ishmuratova M.M. Osobennosti biologii i tsenopopulyatsionnye kharakteristiki vidov roda Tulipa L. na Yuzhnom Urale [Features of biology and cenopopulation characteristics of species of the genus Tulipa L. in the southern Urals]. Vestnik Udmurtskogo universiteta. Seriya «Biologiya. Nauki o Zemle» [Bulletin of the Udmurt University. Series « Biology. earth science»], 2015, no. 2, pp. 101-108.

3. Ryabinina Z.N., Didenko E.N. Populyatsionnye issledovaniya nekotorykh vidov semeystva Liliaceae [Population studies of some species of the family Liliaceae]. Izvestiya Orenburgskogo gosudarstvennogo agrarnogo universiteta [Izvestiya Orenburg state agrarian University], 2007, vol. 3, no. 15-1, pp. 19-23.

4. Kashin A.S., Petrova N.A., Shilova I.V., Korneev M.G., Ermolaeva N.N. Struktura tsenopopulyatsiy Tulipa gesneriana L.(Liliaceae) v Saratovskoy oblasti [Structure of coenopopulations of Tulipa gesneriana L. (Liliaceae) in Saratov 
region]. Bioraznoobrazie aridnykh ekosistem [Biodiversity of arid ecosystems], 2014, pp. 86-105.

5. Kutlunina N. A., Polezhaeva M. A., Permyakova M. V. Morphologic and AFLP analysis of relationships between tulip species Tulipa biebersteiniana (Liliaceae). Russian journal of genetics, 2013, vol. 49, no 4, pp. 401-410.

6. Shorina N.I., Smirnova O.V. The Population Biology of Ephemeroids. The Population Structure of Vegetation. Springer, Dordrecht, 1985, pp. 225-240.

7. Zonneveld J.M. The systematic value of nuclear genome size for «all» species of Tulipa L. (Liliaceae). Plant Systematics and Evolution, 2009, vol. 281, pp. 217-245.

8. Chernysheva O., Bukin Y., Krivenko D. The morphometric characters variability analysis of Tulipa uniflora (Liliaceae) in the Angara Region (Irkutsk Oblast, Russia). BIO Web of Conferences. EDP Sciences, 2018, 21 August 2018, vol. 11. P. 00009.

9. Van Raamsdonk L.W.D., De Vries T. Species relationships and taxonomy in Tulipa subg. Tulipa (Liliaceae). Plant Systematics and Evolution, 1995, vol. 195, no. 1-2, pp. 13-44.

10. Lyu T.N., Ochirova A.S., Lidzhieva N.Ts. Izmenchivost' morfologicheskikh priznakov rasteniy i vitalitetnaya struktura tsenopopulyatsiy vidov roda Tulipa (Liliaceae) v zapovednike «Chernye zemli» [The variability of morphological features in plants and vitality structure of cenopopulations of species of genus Tulipa (Liliaceae) in the natural reserve «The Black soil»]. Izvestiya Samarskogo nauchnogo tsentra Rossiyskoy akademii nauk [Izvestiya of the Samara Scientific Center of the Russian Academy of Sciences], 2016, vol. 1, no. 5 (2), pp. 314-319.

11. Krasnaya kniga Rossiyskoy Federatsii (rasteniya i griby)[ Red Book of the Russian Federation (plants and mushrooms)]. Moscow: KMK Scientific Partnership, 2008. 885 p.

12. Krasnaya kniga Krasnodarskogo kraya. (Rasteniya i griby) [Red Book of Krasnodar Territory. (Plants and mushrooms)]. Krasnodar: OPO « Design Bureau № $1 », 2007.640 \mathrm{p}$.

13. Krasnaya kniga Rostovskoy oblasti: $v 2$ t. Rasteniya i griby [The Red Book of the Rostov region: in 2 tons. Plants and mushrooms]. Rostov-on-Don: Ministry of Natural Resources of the Rostov Region, 2014. vol. 2. 344 p.

14. Krasnaya kniga Respubliki Kalmykiya: v 2 t. Redkie i nakhodyashchiesya pod ugrozoy ischeznoveniya rasteniya i griby [The Red Book of the Republic of Kalmykia: in 2 vol. Rare and endangered plants and mushrooms]. Elista: ZAOr «SPE «Dzhangar», 2014. vol. 2. 199 p. 
15. Tsenopopulyatsii rasteniy (osnovnye ponyatiya i struktura) [Cenopopulation of plants (basic concepts and structure)]. M.: Science, 1976. 217 p.

16. Tsenopopulyatsiy rasteniy [Cenopopulation of plants]. M.: Science, 1977. 173 p.

17. Zlobin Yu.A. Printsipy i metody izucheniya tsenoticheskikh populyatsiy rasteniy [Principles and methods of studying coenotic plant populations]. $1989.146 \mathrm{p}$.

18. Uranov A.A. Zhiznennoe sostoyanie vida v rastitel'nom soobshchestve [The life condition of the species in the plant community]. Byul. MOIP. Otdelenie biol. [Bull. of the MOIP. Ser.of Biology], 1960, vol. 65, issue 3, pp. 77-92.

19. Uranov A.A. Ontogenez i vozrastnoy sostav populyatsiy [Ontogeny and age composition of populations]. Ontogenez $i$ vozrastnoy sostav populyatsiy tsvetkovykh rasteniy [Ontogeny and age composition of populations of flowering plants]. M.: Science, 1967, pp. 3-8.

20. Ishbirdin A.R., Ishmuratova M.M. K otsenke vitaliteta tsenopopulyatsiy Rhodiola iremelica Boriss. po razmernomu spektru [To assess the vitality of coenopopulations of Rhodiola iremelica Boriss. on the size spectrum]. Fundamental'nye $i$ prikladnye problemy populyatsionnoy biologii [Fundamental and applied problems of population biology], 2004, pp. 80-85.

\section{ДАННЫЕ ОБ АВТОРЕ}

Очирова Александра Сергеевна, аспирант

Федеральное государственное бюджетное общеобразовательное учреждение высшего образования «Калмыикий государственный университет имени Б.Б. Городовикова»

ул. Пушкина, 11. г. Элиста, 358009, Российская Федеращия ochirowa.alex@yandex.ru

\section{DATA ABOUT THE AUTHOR}

Ochirova Aleksandra Sergeevna, Postgraduate Student

Kalmyk State University named after B.B. Gorodovikova

11, Pushkin str., Elista, 358009, Russian Federation

ochirowa.alex@yandex.ru

ORCID: 0000-0001-9924-3368 